\section{Commentary: Unilateral pulmonary artery agenesis and lung cancer: Sharks on one side, bears on the other}

\section{Blair Marshall, MD, and Abby White, DO}

Matsumoto and colleagues ${ }^{1}$ have reported on thoracoscopic lobectomy for lung cancer in a patient with unilateral, ipsilateral pulmonary artery agenesis. They have highlighted the technical challenges with intraoperative images and video. In contrast to the usual operation-naive patient, these patients have had critical changes to their anatomy and physiology that affects the operative and postoperative morbidity.

The critical question to address is whether the cancer is ipsilateral or contralateral to the pulmonary artery agenesis. If ipsilateral, as reported in their study, the amount of pulmonary function removed with lobectomy, or even pneumonectomy, will likely be minimal. Intraoperative single-lung ventilation will not be problematic from a hypoxemic standpoint. However, it is the systemic collaterals that create the intraoperative challenges. Bleeding from hypertrophic intercostal, bronchial, phrenic, coronary, and other systemic collaterals can be seen. ${ }^{2}$ In their report, the authors used an endoscopic clip applier as an alternative to a vessel sealing device because of the failure of the latter as an effective method of hemostasis. ${ }^{1}$ Chronic infections often plague the ipsilateral (malperfused) lung and, as such, dense pleural adhesions can also be encountered. ${ }^{3}$

However, cancer contralateral to the pulmonary artery agenesis poses a unique set of challenges. Critical when operating on the contralateral lung is that most, if not all, the patient's pulmonary function will be derived from the

\footnotetext{
From the Division of Thoracic Surgery, Department of Surgery, Brigham and Women's Hospital, Harvard Medical School, Boston, Mass.

Disclosures: The authors reported no conflicts of interest.

The Journal policy requires editors and reviewers to disclose conflicts of interest and to decline handling or reviewing manuscripts for which they may have a conflict of interest. The editors and reviewers of this article have no conflicts of interest.

Received for publication June 11, 2020; revisions received June 11, 2020; accepted for publication June 17, 2020; available ahead of print June 24, 2020.

Address for reprints: M. Blair Marshall, MD, Division of Thoracic Surgery, Department of Surgery, Brigham and Women's Hospital, 75 Francis St, Harvard Medical School, Boston, MA 02115 (E-mail: mmarshall16@bwh.harvard.edu).

JTCVS Techniques 2020;3:346-7

2666-2507

Copyright (C) 2020 The Authors. Published by Elsevier Inc. on behalf of The American Association for Thoracic Surgery. This is an open access article under the CC BY-NCND license (http://creativecommons.org/licenses/by-nc-nd/4.0/).

https://doi.org/10.1016/j.xjtc.2020.06.031
}

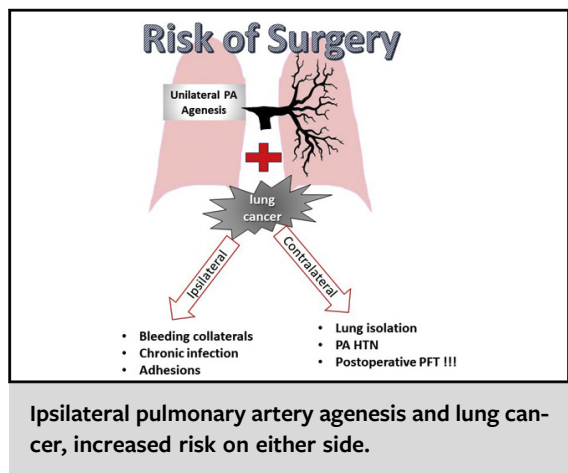

CENTRAL MESSAGE

The operative risks in patients with pulmonary artery agenesis and lung cancer are determined by the side that the cancer arises on, ipsilateral or contralateral.

lung with normal perfusion. The effect of lobectomy in these patients will be far greater than the effect in patients with normal pulmonary arterial anatomy. A thoughtful preoperative evaluation of these patients must include a quantitative and qualitative ventilation-perfusion study to allow for more accurate prediction of the patient's postoperative pulmonary function. Pulmonary artery hypertension can result in these patients, making intraoperative dissection and division of pulmonary arterial trunks challenging. A preoperative echocardiogram will identify such patients and delineate any associated right ventricular dilation or dysfunction. Finally, one must expect that lung isolation and single-lung ventilation of the contralateral lung during minimally invasive surgery will be a challenge, similar to that experienced when performing pulmonary resection in patients with previous pneumonectomy. In such situations, the use of intrathoracic carbon dioxide insufflation could be an effective alternative to single lung ventilation. ${ }^{4}$ In summary, patients presenting with unilateral pulmonary artery agenesis and lung cancer have increased operative risks. These risks are specific to the side that each arise on, ipsilateral versus contralateral; thus, sharks on one side and bears on the other.

\section{References}

1. Matsumoto D, Toba H, Kondo K, Tangoku A. Thoracoscopic lobectomy for lung cancer with unilateral absence of pulmonary artery. J Thorac Cardiovasc Surg Tech. 2020;3:343-5.

2. Gupta K, Livesay JJ, Lufschanowski R. Absent right pulmonary artery with coronary collaterals supplying the affected lung. Circulation. 2001;104:E12-3. 
3. Wang P, Yuan L, Shi J, Xu Z. Isolated unilateral absence of pulmonary artery in adulthood: a clinical analysis of 65 cases from a case series and systematic review. J Thorac Dis. 2017;9:4988-96.
4. Caso R, Kelly CH, Marshall MB. Single lumen endotracheal intubation with carbon dioxide insufflation for lung isolation in thoracic surgery. Surg Endosc. 2019; 33:3287-90. 